\title{
Património, turismo e emoção
}

Heritage, Tourism and Emotion

Patrimoine, tourisme et émotion

\section{Carlos Fortuna}

\section{(2) OpenEdition}

\section{Journals}

Edição electrónica

URL: http://journals.openedition.org/rccs/4898

DOI: $10.4000 /$ rccs.4898

ISSN: 2182-7435

\section{Editora}

Centro de Estudos Sociais da Universidade de Coimbra

\section{Edição impressa}

Data de publição: 1 Junho 2012

Paginação: 23-40

ISSN: 0254-1106

\section{Refêrencia eletrónica}

Carlos Fortuna, «Património, turismo e emoção », Revista Crítica de Ciências Sociais [Online], 97 | 2012, colocado online no dia 19 abril 2013, criado a 19 abril 2019. URL : http://journals.openedition.org/ rccs/4898; DOI : 10.4000/rccs.4898 


\section{CARLOS FORTUNA}

\section{Património, turismo e emoção}

Depois de discutir a relação entre património e tradição, este texto trata da complexidade da atribuição de significado ao património, aos objetos, lugares ou práticas socioculturais. O turismo surge como um poderoso meio da valorização emocional do significado patrimonial desses objetos, lugares e práticas sociais. A atual busca de experiências emocionais continua a tomar lugar central no desenvolvimento do turismo de memória, mas também no turismo negro e no da realidade. Os diferentes modos da sua perceção são vistos como modalidades de disputa social de sentidos, incluindo as narrativas pós-coloniais do turismo. Nestes dias de valorização da experiência psicoemocional dos turistas, admite-se que a oferta turística de forte sentido emocional possa aumentar acentuadamente em todo o mundo.

Palavras-chave: lugares; memórias; objetos; património; práticas socioculturais; turismo - aspetos psicoemocionais.

\section{Introdução}

Estamos a viver tempos de ameaças e riscos constantes, em que (des)crever o mundo se tornou um exercício deveras complexo. Não dispomos dos referentes robustos, políticos, culturais, ideológicos que ordenavam a análise e a interpretação do mundo de há décadas atrás. 1989, o ano da queda do Muro de Berlim, é desse ponto de vista um marco importantíssimo. Com ele, colapsaram muitas das convicções políticas e ideológicas que sustentavam corajosas descrições e classificações do mundo, ao mesmo tempo que se disseminaram as raízes do neoliberalismo que naturaliza e fragiliza a discussão política e académica.

Neste contexto, também a reflexão sobre os patrimónios e o turismo se renova na sua atualidade. Refletir sobre as relações existentes entre estes dois domínios da realidade cultural, conduz-nos não apenas a colocar em perspetiva os modos como se alimentam reciprocamente, mas também as modalidades sob as quais interferem nos comportamentos e nas convicções acerca da sociedade.

No que respeita à relação do património com o turismo e a sociedade, gostaria de começar por enunciar uma premissa, hoje razoavelmente 
divulgada, segundo a qual as ações de conservação e proteção do património não têm qualquer relação direta com a ideia que atribui aos seres humanos um inabalável desejo de conservar e manter as suas tradições e modos de vida. Não nego que transmitir às futuras gerações a tradição cultural seja um imperioso desígnio político e cultural da humanidade, mas entendo que o argumento da conservação e proteção do património tem a sua própria autonomia institucional e não pode ser confundido com a manutenção de quaisquer tradições socioculturais das comunidades e nações. ${ }^{1}$

\section{Património e tradição}

O que significa afirmar que conservar o património não equivale a conservar a tradição cultural?

Em primeiro lugar, a diferença reside no facto de a tradição, entendida como reprodução cultural de padrões comportamentais e modos de pensamento e ação, aflorar a todo o momento nas nossas práticas sociais, mostrando uma vivacidade e um dinamismo que, por um lado, a tornam atual, permanentemente renovada e quase plástica e, por outro lado, alimentam um sentido reconfortante de proximidade do passado social. Ao invés deste sentido de proximidade do presente com o passado típico da tradição, a prática institucional da conservação do património exige, antes de mais, que seja criada uma distância histórica, pela qual os objetos, lugares ou as práticas sociais podem ser vistos como documentos de um passado mais ou menos longínquo. A criação desta distância temporal é essencial para que se possa nomear e dar significado próprio ao património. Com efeito, é nela que reside o ato patrimonial, entendido como capacidade das instituições políticas para definirem o que é ou não é património histórico e cultural e, deste modo, estipularem o que deve ou não ser objeto da proteção/conservação e, assim, de consagração e reconhecimento social alargado.

$\mathrm{O}$ ato patrimonial refere-se em regra à consagração de determinados objetos, lugares ou práticas socioculturais que surgem (re)investidos de significado histórico, mesmo se despojados de qualquer vinculação constitutiva do que é a vida coletiva atual e, por igual, do que possam ter sido a suas funções e o seu significado no passado. Este processo, a que chamei de "destradicionalização da tradição" (Fortuna, 1997), implica reconhecer a autonomização ontológica dos bens patrimonializados. Por outras palavras,

\footnotetext{
${ }^{1} \mathrm{Na}$ verdade, de acordo com Neil Silberman, o excesso de preservação patrimonial para que a moderna indústria do turismo contribui pode conduzir à paródia de nações e de comunidades, em vista do exagerado esforço de as fazer corresponder aos desígnios do turismo de massas contemporâneo (Silberman, 1996).
} 
se não constituem elementos significativamente vinculados ao quotidiano atual dos sujeitos, os objetos, lugares ou práticas socioculturais patrimonializados passam, ipso facto, a ser entendidos como fim em si mesmos. Podem, então, por efeito da distância temporal que sustenta o seu reconhecimento enquanto património, surgir desligados da realidade imediata e do presente vivido, assim como também desvinculados dos usos sociais concretos que terão servido.

Torna-se deste modo clara a distinção dos aspetos culturais, materiais e simbólicos que constituem o que designamos por tradição. O mais trivial ato social, ou o uso descomprometido de alguns instrumentos e, de modo semelhante, o prosaico uso da linguagem, ou maneiras familiares de proceder são elementos constitutivos da tradição e são, por isso, exercitados comumente, sem recurso a quaisquer protocolos mentais ou práticos. O seu uso corrente constitui a mais elementar prática de manutenção da tradição, distanciando-se portanto da elaboração conceptual e seleção que preside à definição do património.

Isto não significa sustentar que a vida social pode seguir o seu decurso normal sem a presença do património. As estratégias patrimonialistas dos nossos dias procuram fundamentar a sua ação na salvaguarda exclusiva dos recursos materiais e culturais em risco de desaparecimento. Mas sabemos como essa é uma retórica falaciosa. Os tempos de hoje são de manifesta inflação patrimonial e, enquanto tal, a patrimonialização serve também os propósitos do mercado e do turismo. A inflação patrimonialista tem limites de eficácia, que tornam legítima a interrogação de Henri-Pierre Jeudy sobre se a ação futura de defesa do património não residirá na imperiosa destruição seletiva, ou na desclassificação de alguns dos bens consagrados como tal (Jeudy, 2008).

Os objetos, lugares ou práticas socioculturais patrimonializados têm significados histórico-culturais consagrados que destacam qualidades e valores mnemónicos, estéticos ou técnico-científicos que estão para além do sentido e do valor originais diretamente associados à sua utilidade prática de outrora. A questão que se coloca aqui - para me manter fiel à ideia inicial da turbulência dos tempos que vivemos e da complexidade da classificação quando se desmoronam antigas certezas epistemológicas e teóricas - é a de saber qual o significado atual conferido ao património e a quem pertence a responsabilidade da sua definição.

Recorro ao clássico intérprete do "culto moderno dos monumentos" - o austríaco Aloïs Riegl (1858-1905) - que sustentava que o significado dos monumentos não corresponde ao que essas obras possam ter sido ou possam ter representado, nem aos propósitos que possam ter servido, 
além de, muitas vezes, não terem sequer correspondência com o próprio destino original que lhes foi atribuído. Ao contrário, para Riegl, são os sujeitos modernos os principais responsáveis pela atribuição do valor e significado atuais desses bens e recursos (Riegl, 1984). Nós - os sujeitos modernos - procedemos então a uma atualização do significado do património de acordo com os nossos próprios sistemas de valorização e, desse modo, transferimos significados operativos diversos para objetos, lugares ou práticas socioculturais que, oriundos de um passado mais ou menos remoto, atualizam patrimonialmente o presente com o qual se procuram harmonizar (Choay, 2006).

Este é um domínio fantástico para a nossa reflexão. A proposta de definição do valor patrimonial de Riegl, no entanto, deixa uma questão em aberto: Qual é, na verdade, a verdadeira fonte do valor e do significado do património em geral? A dificuldade principal reside na identificação dos agentes produtores de significado patrimonial inscrito nos bens classificados, sendo que se abre aqui um vastíssimo leque de possibilidades. Essa atribuição de sentido pode ser um exercício a que se entregam numerosos atores sociais. De um lado, ela tanto pode ser vista como competência própria de agentes especializados - académicos, cientistas, técnicos - incluindo agentes diretamente ligados ao mercado do património - empresários, promotores, jornalistas ou operadores turísticos. De outro lado, essa classificação e atribuição de significado ao património pode ser fruto da prática dos próprios turistas que, enquanto recetores e consumidores diretos de património não se isentam de conferir livremente atributos e significados singulares a objetos, lugares ou práticas do seu consumo turístico, da mesma forma que pode também resultar do trabalho de cidadãos, associações e movimentos cívicos, políticos ou sociais.

A questão da atribuição de valor está intimamente associada à própria natureza do património em causa. Por exemplo, no caso de atos simbólicos e de celebração histórica, em princípio, esse valor tende a ser atribuído em exclusivo por especialistas. Já no caso do valor histórico de determinada obra ou lugar, pode ocorrer que o seu valor seja "consensualizado" em atos informais de negociação ou confronto informal entre especialistas e público, ao mesmo tempo. É assim que ocorre, por exemplo, com muitas situações de atribuição de valor patrimonial local ou concelhio, cujo reconhecimento decorre de ações de participação da coletividade municipal.

Outras vezes, em casos não institucionalmente consagrados, são os recetores diretos, como os turistas desvinculados da realidade contextual, que lhe dão sentido próprio, como no caso de vestígios do passado cultural que tendem a recolher significado pelo simples facto de serem julgados exemplares de uma 
qualquer antiguidade. Em diversas circunstâncias, acrescente-se, o significado do património é objeto de interpretações díspares de técnicos especialistas e de consumidores turistas. Os primeiros tendem a avaliar as situações de acordo com critérios elitistas de validação patrimonial que reclamam um dado sentido universalista; não raro, os segundos tendem a valorizar espontaneamente manifestações materiais ou imateriais de cultura popular do que julgam dever ser historicamente relevante para determinada comunidade. O diálogo entre uma e outra destas abordagens é praticamente inexistente, a não ser na mediação que pode resultar de encontros, congressos ou textos que se dedicam a procurar decifrar a razão de ser e o modo como se opera este confronto de tecnicidades e ideologias.

\section{Turismo e emoção}

A ausência de diálogo direto entre visões diferentes do sentido do património não significa que a definição do que é o património cultural não possa ser entendida como resultante de um processo de negociação de sentidos e significados disputados. Por isso, até os consagrados valores abstratos atribuídos habitualmente ao património histórico - por exemplo, antiguidade, autenticidade, raridade ou beleza - podem ver o seu sentido alterado quando o caráter emocional, social ou político dos recetores se vem adicionar aos critérios mais pragmáticos de especialistas. Na verdade, existe hoje uma manifesta valorização dos efeitos práticos da emoção (ou da emoção coletiva) resultante da dramaticidade da presença, por exemplo, de um objeto ou bem patrimonial de caráter sublime em resultado do seu exclusivismo estético ou da sua raridade histórica. ${ }^{2}$ Evidentemente que o conceito de emoção que estou a utilizar aqui é subsidiário da conceção que o neurocientista António Damásio (2012) apresenta sobre o modo como o organismo responde aos estímulos exteriores tal como estes são processados pelo cérebro. O processo pode ser mais ou menos consciente, sendo que o sentido em que estou a referir-me à emoção é o da reação do corpo que ocorre de forma autónoma, isto é, um processo não necessariamente consciente por parte dos sujeitos. Esta noção é a que surge mais frequentemente tratada nas ciências sociais que se aproxima da noção de sentimento e afeto.

Nesta linha de raciocínio, podemos admitir, recorrendo a David Lowenthal (1975: 52-67), que a emoção pode estar diretamente associada ao sentimento de partilha de um tempo passado que a antiguidade das coisas e dos lugares pode suscitar em cada um de nós. Trata-se de uma sensação

\footnotetext{
${ }^{2}$ Não nos dedicaremos neste texto à análise das origens desta possibilidade para nos dedicarmos mais detalhadamente aos seus efeitos.
} 
muito particular resultante de poder visitar, presenciar ou mesmo tocar testemunhos, quiçá únicos, do passado cultural ou arquitetónico mais ou menos significativo. A antiguidade do património promove um sentimento de proximidade com uma comunidade (imaginada?) de equilíbrios entre tecnologia, arte, cultura e natureza que se mostra reconfortante e nos emociona perante a atual desorganização do presente. ${ }^{3}$ Por outro lado, contudo, da apreciação dos vestígios do passado resulta também uma sensação da presença de um original ou de algo cuja raridade nos transmite um sentimento de excecionalidade, que recolhe alto apreço entre os sujeitos numa cultura de repetição e cópia como a cultura contemporânea do consumo. A perceção do passado como continuidade e sequência é uma sensação que o património permite experienciar, na medida em que transmite a ideia de cumulatividade, que não é mais que um processo cultural no qual nos sentimos envolvidos na condição dupla de herdeiros e transmissores. Tal condição prolonga-se na noção de finalismo que o património ostenta e que, com frequência, é convertível em sinal de estabilidade pessoal ou civilizacional, associada que está ao reconhecimento da capacidade de finalização de um projeto, contrariando o vulgar sentimento de culpa pela obra inacabada que, em si, enuncia um presente de desordem e um futuro comprometido que parece não poder iniciar-se.

A estes atributos do património histórico e em particular dos monumentos, podemos acrescentar outras qualidades que interferem com as condições psicoemotivas da sua receção por parte de visitantes e turistas. Natalie Heinich faz destacar como a autenticidade provoca uma emoção em redor dos aspetos do seu estado atual e da sua origem (Heinich, 2009: 66-67). Do mesmo modo que a sua simples presença pode gerar comoção em torno de uma edificação ou da memória de um personagem célebre que ali viveu, trabalhou, ou morreu, ou que, mais prosaicamente, possa simplesmente ter feito uso deste ou daquele artefacto por mais trivial que seja. Mas também a beleza dos monumentos nos reenvia para uma seleção estética de elementos mais salientes da sua representatividade (ibidem: 244). Estamos perante, portanto, um elemento emocional e dramático que, a meu ver, só raramente é tido em conta no ato da apreciação do valor patrimonial e do significado atribuído a objetos, lugares ou práticas do passado.

\footnotetext{
3 O filósofo e sociólogo alemão Georg Simmel desenvolveu de forma original este tema num texto de 1911, dedicado à ruína e acerca da relação conflitual entre cultura e natureza. Para Simmel, a ruína milenária exala um sentimento de paz e temperança resultante do desfecho telúrico em que a obra humana (a cultura) sucumbe perante a força da natureza (o desabamento do edificado) e um novo equilíbrio de fatores se reestabelece (Simmel, 1959). Adiante regressaremos ao tema da emoção gerada pela contemplação das ruínas.
} 
Esta digressão pelas qualidades dos bens patrimonializados do passado permite reconhecer o potencial de estimulação psicológica contido no ato da receção ou consumo turístico do património histórico. Ao contrário das teses que sustentaram que a massificação das tecnologias de informação e comunicação - de que o turismo moderno é um exemplo -, dedicadas à reprodução de imagens e referências de elementos salientes do património construído ou natural, fariam diminuir o impacto emocional gerado sobre os sujeitos - teses que recuam até à problematização de Walter Benjamin em torno da obra de arte na era da reprodutividade técnica (Benjamin, 1992) -, o certo é que essas tecnologias tendem a ampliar, em vez de fazer diminuir, o grau de satisfação e comoção pessoal geradas no contacto imediato com o objeto patrimonializado.

Nesta linha de ideias, como assinalei já em outro lugar (Fortuna 1999: 32), Chris Rojek refere-se a Pierre de Coubertin - o pai dos Jogos Olímpicos modernos - que, em 1896, inscrevia no seu diário as "supremas sensações" que as ruínas de Olímpia lhe transmitiram:

Deixei-me ficar a ver o sol nascer, e logo que os primeiros raios de luz invadiram o vale, apressei-me a chegar às ruínas. [...] Era uma arquitetura moral aquela onde eu ia buscar ensinamentos; e eis que ela se ampliou em todas as suas dimensões. A minha meditação durou toda a manhã. [...] Por toda a manhã deixei-me andar a divagar por entre as ruínas. (Coubertin apud Rojek, 1993: 113)

A estranha capacidade que Pierre de Coubertin regista de as ruínas poderem suspender o presente vivido dos visitantes e promover a sua divagação é efeito direto e conjugado do modo como os atributos dos bens patrimonializados históricos e monumentais - antiguidade, raridade, continuidade, sequência, finalismo, autenticidade e beleza - podem atuar psicologicamente sobre os recetores de arte em geral e os turistas em particular. O mentor dos modernos Jogos Olímpicos, perante as ruínas revela ainda um manifesto sentimento de melancolia que é um traço característico da visão romântica de artistas, escritores e poetas, tratado de modo cativante por Christopher Woodward (2002).

Acrescentaríamos, para sermos mais precisos, que, de acordo com o contributo de Walter Benjamin, o estado de intensa concentração com que os sujeitos percecionam os objetos artísticos ou a arte da arquitetura, no contexto turístico ou outro, pode resultar em que sejam os sujeitos observadores a ser absorvidos pelos objetos, em contraste com a perceção em estado de distração em que são os objetos que são absorvidos pelos sujeitos (Benjamin, 1992: 109). Não são diretamente as experiências vividas que geram a reação 
emocional dos sujeitos, mas antes a interpretação que estes fazem dessas circunstâncias. Além disso, admitimos que a emoção que um determinado indivíduo experimenta em dado momento depende do seu grau de pertença e identificação com o panorama cultural envolvente. Dito de outra forma, as emoções são modos particulares de ligação dos sujeitos às comunidades e são tanto mais significativas quanto maior é o seu sentimento de participação coletiva nessas comunidades (Le Breton, 2009: 126).

Retomando aqui a referência à noção de emoção como sentimento, já anteriormente referida, entramos no domínio das modificações do corpo suscitadas de modo mais ou menos autónomo pelos estímulos e pulsões exteriores. Trata-se de dimensões não conscientes equivalentes a sentimentos que geram uma resposta fisiológica do corpo que não é direta nem linear. Quer isto dizer que a reação dos indivíduos ao mesmo estímulo é diversa, além de poder ser condicionada por outros elementos como a memória ou o conhecimento de reações e experiências vividas por outros. Ora, como se tem feito notar, o sentimento de extrema agradabilidade e de completa evasão resultante do contacto de Pierre de Coubertin com as ruínas de Olímpia requer um grau de identificação com outros membros ou parceiros com quem o significado simbólico do lugar possa ser partilhado. Noutras circunstâncias similares, os lugares desejados semelhantes aos relatados por Coubertin, podem, no limite, resultar no sentimento de "perda da noção de realidade" e conduzir mesmo à condição de desequilíbrio psicoemocional a que se convencionou chamar "síndrome de Stendhal". Trata-se de um estado patológico, não-consciente, de perturbação psíquica dos indivíduos - vertigens, taquicardia, alucinações - resultante da intensa comoção gerada pelo seu confronto com a beleza e a perfeição dos objetos ou lugares visitados (Magherini, 1989), sentimento esse que é culturalmente partilhado com outros que, como no caso de Stendhal, expressam um profundo sentido de evasão romântica.

Este estado de coisas deve ser reconhecido não apenas enquanto ingrediente importante de qualquer estratégia promocional de turismo histórico e monumental, mas também como traço de política patrimonial em geral. Perante a atual inflação conservadorista de objetos, lugares ou tradições socioculturais do passado - que parece intensificar-se em momentos de crise económica e social - o recurso à patrimonialização parece caucionar o que Jean Baudrillard gostava de enunciar a propósito da cultura do consumo: são os objetos, os lugares e as práticas socioculturais ditas tradicionais que nos conservam a nós e não nós que os conservamos a eles.

A relação do património com o passado está hoje diretamente envolvida na discussão sobre o lugar da memória na sociedade contemporânea. A relação desse facto com a atividade turística é reveladora da centralidade que a 
dimensão histórica e cultural tem em certas tipologias do turismo moderno. Vivemos hoje seduzidos e verdadeiramente cercados pela memória coletiva, a sua objetivação e a sua narrativa. Muitas cidades turísticas contemporâneas devem precisamente à valorização do seu passado a importância que ostentam enquanto lugares de atração de visitantes num mercado internacional de elevada competitividade (Sturken, 2007).

Berlim, por exemplo, é um desses casos de forte inter-relação do turismo com o património e a memória da cidade, assente numa impressionante narrativa histórica sobre o passado da cidade. ${ }^{4} \mathrm{O}$ turismo é efetivamente o principal agente e beneficiário desta nova indústria que sendo urbana e cultural é do património também. Convém recordar, no entanto, que já na década de 20 do século passado, Robert Musil, que ficaria célebre pela edição do seu O homem sem qualidades, escreveu acerca de Berlim para denunciar o paradoxo da invisibilidade dos monumentos públicos. Musil pretendia com a sua crítica afirmar que o nosso desconhecimento sobre os monumentos antigos, a sua verdadeira história, a identidade dos seus ocupantes e a natureza dos cerimoniais que ali se desenrolaram, é gerador de um sentimento de indiferença que contrasta de modo gritante com o que acabamos de dizer acerca da sua capacidade de emocionar e comover. Essa indiferença, em muitos casos repartida por igual entre turistas e residentes locais, faz com que olhemos os edifícios, os monumentos e o património em geral com o mesmo desprendimento que ocorreria se o monumento ali não estivesse. Paradoxalmente, segundo Musil, esta invisibilização mental do monumento agrava-se à medida que se repetem, a cada passo, de um lado e outro da rua, monumentos e obras de valor arquitetónico e patrimonial inestimável, sobre os quais nada nos é ensinado e perante os quais passamos indiferentes. A mensagem reside na necessidade de educação sobre a história e o património das cidades, sem a qual a memória coletiva parece deixar-se apagar, o que, por sua vez, produz efeitos negativos sobre o potencial de atração turística local, como muito bem conhecem os profissionais do setor.

É inegável a atualidade desta relação entre turismo, educação e memória. Por um lado, podemos ter em consideração a verdadeira corrida aos marcadores da história e da memória locais que assinala a prática de inúmeras políticas patrimonialistas de hoje. De outro lado, vale a pena interrogarmo-nos

\footnotetext{
${ }^{4}$ Em estudo recente sobre a cidade de Coimbra foi testada esta hipótese da relação íntima existente entre turismo e património. Com efeito, a estratégia turística de Coimbra desenrola-se, fundamentalmente, em torno de um único recurso histórico-patrimonial - a Universidade - tanto no plano do edificado como no plano do intangível, sendo essa a base da recente candidatura da cidade a Património Cultural da Humanidade, o que revela, portanto, a ausência de valorização de outros possíveis patrimónios urbano-culturais locais (Fortuna et al., 2012).
} 
sobre o papel que, invertido no seu sentido, tem a estratégia artística seguida por Christo Javacheff e Jeanne Claude, que se plasma em fazer recobrir, logo, em tornar invisíveis, lugares singulares e construções únicas da arquitetura monumental mas também da natureza. Será esta uma forma paradoxal de revelar escondendo? Podemos admitir que sim, se tivermos em consideração os milhares de visitantes e turistas que acorreram a admirar a estética do embrulho com que os consagrados artistas mantiveram envolvido o Reichtag berlinense durante 14 dias, em junho de 1995.5

A sedução (ou a emoção) que o monumento gera sobre os públicos está ameaçada pela sua contínua repetição e, sobretudo, pela ausência de informação sobre o seu real significado. Nas palavras do filósofo alemão contemporâneo Andreas Huyssen, tal sentimento encontra-se traduzido na paradoxal afirmação segundo a qual Berlim está a tornar-se invisível porque nada há de menos visível do que um monumento (Huyssen, 2003: 32). A esta luz, as conhecidas iniciativas artísticas de Christo e Jeanne Claude são a demonstração do sentido real da monumentalidade que encontra no "desaparecimento" (temporário) dos monumentos uma das mais inesperadas expressões do seu valor e da sua narrativa.

Mas voltemos à questão da relação do património com a memória. Como a memória tem uma concretização fundamentalmente espacial, podemos afirmar que o século xx foi um século marcado pela hipertrofia da memória, com o surto de consagrações de lugares de memória coletiva. Adotámos os lugares de memória para registo dos "ambientes" desaparecidos que terão tido expressão em territórios circunscritos precisos. Metaforicamente, foi como se nos tivéssemos concentrado nos vestígios do passado para podermos conservar os sinais das nossas raízes identitárias mais significativas, o que implica uma reconstituição simbólica de intimidades territorializadas, ou o que podemos designar por "microterritorialidades" (Fortuna, 2012). Casos há em que o turismo que se alimenta da memória e da monumentalidade dos lugares parece pretender compensar os sujeitos pela perda da sua identidade cultural e a identidade dos povos como nação ou coletividade. ${ }^{6}$

\footnotetext{
${ }^{5}$ No campo da música, a célebre composição de John Cage - 4'33" - do mesmo modo que, no domínio do cinema, a "Branca de Neve" do português João César Monteiro, invertem o sentido convencional da performance artística e partilham alguns dos traços do paroxismo estético e emocional a que a arte pode conduzir como no caso das criações de J. Christo e J. Claude.

${ }^{6}$ Nesta hipótese revela-se grande parte do potencial heurístico da noção de "espaço de compensação", desenvolvida por Wong Chong Thai para significar o lugar onde se encontram as mais diversas subjetividades e que, por isso, pode representar um espaço alternativo aos espaços demarcados dos interesses pessoais ou de grupos (Thai, 1997). O turismo, enquanto busca de espaços e experiências pessoais alternativas, pode ser interpretado como gerador desta possibilidade de espaços de "compensação", incluindo nos espaços histórico-monumentais que, como defendi noutro lugar, alimentam a busca de raízes identitárias (Fortuna, 1999: 23-44).
} 
Noutros casos, ao contrário, é como se esta identidade receasse ser mostrada por revelar atrocidades e mesmo o horror da história por que passamos, funcionando então como mensagem de alerta contra a não repetição da tragédia. Não é por essa razão que a casa-refúgio de Anne Frank, por exemplo, se tornou um dos principais atrativos turísticos de Amesterdão?

Com efeito, nos nossos dias é o turismo que se torna um dos mais poderosos veículos desta indústria da memória e, mais em particular, dos atropelos e barbarismos da civilização. O dark tourism - expressão que é usada com frequência para assinalar esta apetência pelo passado do horror - encontra-se em manifesto crescendo, ao promover lugares de brutalidade, terror, sofrimento e morte (Janssen e Lagerkvist, 2009). O mesmo sucede com a exploração turística de lugares tornados célebres enquanto marcadores de práticas criminosas, cuja capacidade de atrair curiosos visitantes recua até aos princípios do século XIX, pela ação de agentes e promotores turísticos, mas também de editores e livreiros. Podemos perguntar porque aceitamos e cultivamos hoje esta banalização do horror e este non-sense como sentido paradoxal da história. Assistimos, sem resistência e leve indignação, à sua contínua conversão em atrativos de excelência do lazer e do turismo contemporâneos, captando, com a complacência e o apoio dos Estados, poderosos investimentos do turismo global dedicados à instrumentalização destes lugares e à promoção da narrativa do sofrimento humano que lhes está associada. Tanto a prisão de Nelson Mandela, como os campos de extermínio dos judeus, tanto o ground zero nova-iorquino, como o trabalho exangue de índios nas minas coloniais de Potosi (Bolívia), todos estes lieux de mémoire (Nora, 1986) são vistos como modos de re-presentação de diversas formas mais ou menos exóticas, se não mesmo macabras, de se "pertencer" e compartilhar uma comunidade e uma determinada "experiência" coletiva. ${ }^{7}$ Mesmo quando esta "experiência" se enuncia como sinal de perda cultural e afronta à democracia e à dignidade humana. A ironia do sentido da emoção gerada por tal "experiência" só se compreende por referência ao contexto turístico típico da sociedade pós-emocional de hoje e o barbarismo socio-temperamental que alimenta (Meštrović, 1993).

O que está em causa aqui é a conversão destes espaços do turismo contemporâneo em heterotopias foucaultianas, isto é, lugares carregados de significados inesperados ou estranhos (Foucault, 1986), como os contra-lugares,

\footnotetext{
${ }^{7}$ Ao lado destas propostas turísticas a lugares insólitos do passado de horror e sofrimento, surgem com regularidade alternativas de viagens e experiências alucinantes, até há pouco julgadas apenas como verdadeiras fantasias dignas de criativos utopistas. Assim se compreendem as propostas recentes de turismo de aventura que prometem sensações únicas como as geradas por uma viagem espacial de 10 minutos a uma velocidade de $4200 \mathrm{~km} /$ hora, ou a descida de 2 horas e meia à Fossa das Marianas, no oceano Pacífico, o ponto mais profundo da Terra (11 kms), (Jornal Público, 15.04.2012).
} 
pois que veiculam, a um tempo, narrativas e significados situados localmente e descrições fantasiosas, pelo que estando fora do lugar, têm todavia uma existência real.

Dito isto, pretendo também assinalar o facto de o estado de hipertrofia da memória de hoje ser, em grande parte, alimentado pelo turismo (turismo histórico e cultural, em geral). Com efeito, o turismo tem fomentado numerosas narrativas sobre experiências e identidades com significados continuamente reinterpretados e, frequentemente, moldados a códigos de aceitação estandardizados. O compromisso da sua aceitação parece estar condicionado pela valorização das emoções e as maneiras de ser e de sentir dos sujeitos modernos, mais do que pela visão crítica da história objetiva ou a denúncia da historiografia como instrumento de dominação ideológica (Haroche, 2008). O turismo como prática, e o sujeito pós-turista de que fala John Urry (1990), mostram-se relapsos a qualquer leitura objetiva do passado e da história. Em seu lugar, desconfiam das fantasias do futuro, embora aceitem e promovam ou consumam a sua encenação e se disponham a experienciar o simulacro da realidade encenada, desde que sejam fortes e realistas as emoções que aí possam experimentar.

Que seja o turismo a suscitar esta narrativa dos tempos e dos lugares patrimonializados sobrepostos da nossa cultura não tem em si nada de problemático. Admito até que tenhamos em breve que nos adaptar à turistificação da emoção onde quer que surja a possibilidade de forjar cenários e experiências limite. Estou a pensar, por exemplo, no eventual uso para fins turísticos da experiência, relatada em direto pelas televisões de todo o mundo, de salvamento dos 33 mineiros do deserto de Atacama no Chile, em outubro de 2010. $\mathrm{Na}$ cultura do malsão mercantilismo de hoje não é estranho admitir que possamos estar prestes a assistir a uma operação de mercadorização turística do drama vivido nas minas de San José e à sua irónica transformação num desses lugares mistos da memória de horror e exultação. Nesta linha de ideias não se estranhará o possível surgimento de um tour real ou virtual na cápsula de salvamento que desceu a 700 metros de profundidade, com relatos in vivo e in situ oferecidos aos turistas pelos próprios mineiros ou familiares seus, certamente valorizando as capacidades humanas e o comunitarismo solidário que ali se encontraram ao longo dos 69 dias da dramática ocorrência. ${ }^{8}$ Não é

\footnotetext{
${ }^{8}$ Recorde-se que em 5 de agosto de 2010, um desmoronamento na mina de San José, no deserto do Atacama, deixou 33 operários presos numa galeria. Após 17 dias de sondagens, as equipes de resgate conseguiram contato com o grupo. Deu-se então início a uma cuidadosa e exigente operação de salvamento, inicialmente prevista para durar até quatro meses. Em 13 de outubro, após 69 dias de confinamento, todos os 33 mineiros foram resgatados com vida em ambiente de exaltante operação mediática, com marcas indeléveis de sonante empreendimento político e comercial.
} 
este afinal um dos mais recentes e valorizados patrimónios da humanidade? Não se trata de um dos mais autênticos documentos da realidade e da tenaz resistência humanas, testemunhado em direto por milhões de seres humanos? Não foi um caso de enorme entusiasmo coletivo com a eficácia e os benefícios da ciência e da técnica, ao serviço daquela comunidade e com tão feliz desfecho? Não é esta a narrativa que a sociedade atual, atravessada por desafios de toda a ordem e crises que parecem insolúveis, deseja transmitir ao futuro como testemunho e património de experiências vividas no passado?

Nesta sequência de inesperadas possibilidades do turismo, podemos referir também o papel que a experiência turística tem vindo a ocupar na revelação das geografias de destituição. Slums, townships e favelas encontram-se hoje à mercê do incontido voyeurismo promovido um pouco por todo o Sul global, como denunciam diversos estudos recentes (Sarmento e Brito-Henriques, 2013). Este Sul global está a tornar-se, deste ponto de vista, uma montra de múltiplos repertórios da precariedade quotidiana e do sobrevivencialismo dos pobres como modo de vida. Visitar a pobreza turística é, porventura, a fórmula que melhor sintetiza a perversa usurpação de fragmentos da vida de outros que, mais ou menos encenados e inautênticos, são promovidos e vendidos em packages e websites de numerosas agências turísticas junto de ocasionais visitantes e consumidores abastados. A sua estratégia assenta na exploração e no consumo de experiências, a nova filosofia do reality tourism, internacional e pós-cultural. A experiência da visita à pobreza, que nas palavras de Thope Lakau ilustra como "a miséria de uns é a aventura de outros", 9 sintetiza com eloquência o novo turismo comandado pela condição de alteridade e diferença social, não a diferença histórica ou cultural. Trata-se de uma modalidade de consumo turístico que coloca a pobreza na condição paradoxal de "gerar riqueza", em benefício de agências promotoras e de estratagemas informais diversos (Sharp, 2009: 94-97). À mercê da lógica do turismo, resta saber se a alteridade e a diferença social, depois de convertidas em mercadorias para consumo de elites, poderão ou não e, em caso afirmativo, de que modo instituir mecanismos de capacitação e de emancipação sociopolítica dos indivíduos e das comunidades alvo deste gaze turístico intrometido. De outro lado, perguntamo-nos também se esta experiência, no que ela traduz de cruzamento de fronteiras e de embate cultural, não poderá acarretar um momento de acrescida reflexividade e recontextualização de um mundo de violentas relações dialógicas.

\footnotetext{
9 Thope Lakau é a proprietária de uma hospedaria situada em Khayelistsha, uma township da periferia da Cidade do Cabo, citada por Bianca Freire-Medeiros, num texto que examina os efeitos deste moderno exotismo turístico (Freire-Medeiros, 2010).
} 
Quero dizer que, o que resulta das considerações acerca da sedução/ /emoção gerada pelos monumentos e a sua relação com a memória, quer se trate do dark tourism, ou da visita à pobreza turística, é a necessidade de identificarmos o património cultural como território de uma negociação desigual e de um encontro que forja falsos consensos entre sentidos e significados socialmente disputados. A emoção, como procurei deixar vincado, é certamente um dos lados dessa negociação.

\section{Coda}

Se, como afirmei acima, vivemos hoje num mundo de evidentes incertezas políticas e classificatórias, é claro que enfrentamos uma manifesta dificuldade na definição do que é ou não é património. Admito mesmo que só em democracia seja possível encontrar os termos de um consenso generalizado sobre conceitos e agentes envolvidos na classificação, a um tempo técnica e popular, do que constitui património e o seu significado político. Por um lado, faltam consensos entre especialistas, mas certamente também não existem entendimentos entre estes e o público que pode usufruir da proteção e valorização deste património. Quando se sublinha a cultura da excessiva patrimonialização ou se denuncia a brandura dos critérios de classificação que permite a desmesurada incorporação de demasiados bens nessa categoria de património, creio que a principal parte de tal denúncia reside precisamente nesta dificuldade de estabelecer critérios socialmente negociados, em condições de democraticidade argumentativa e efetiva transparência de sentidos e significados. A ausência de tais critérios robustos traduz-se na própria ausência de negociação de sentidos, o que, por sua vez, conduz a que, em muitas situações indevidas, muitos monumentos e outras marcas culturais se tenham tornado património, do mesmo modo que a "arte" se tornou "cultura", ou a cultura tenha passado a confundir-se com espetáculo.

Em jeito de conclusão, quero fazer assinalar a propósito dos critérios classificatórios desiguais de objetos, lugares e práticas sociais como património e do seu uso turístico, o peso da dimensão política que recai sobre tais desafios classificatórios, também eles sinais da incerteza do nosso presente.

Um caso bem ilustrativo retiro-o da própria evolução do conceito de património por efeito das ações e das políticas de afirmação das identidades e do surgimento de "novos" interesses particularísticos, como ilustram as peripécias em torno dos usos do corpo dissecado de um guerreiro do Botsuana, morto no ano de 1830, às mãos dos especialistas de história natural de inícios do século Xx. Com efeito, o corpo deste guerreiro foi exumado e mumificado, tendo sido trazido para Paris pelos irmãos Verreaux - Jules Pierre e Edouard -, naturalistas franceses, que o colocaram em exposição 
pública até à sua venda ao naturalista catalão Francesc Darder. O naturalista catalão incluiu o corpo do guerreiro na coleção pessoal com que fundaria o museu Darder de História Natural, na cidade de Banyoles, vizinha de Barcelona. Ali, o corpo de guerreiro africano permaneceu em exposição entre 1916 e 1997, quando foi resolvida a denúncia apresentada, em 1991, pelo médico haitiano Alphonse Arcelin contra a exposição que considerava eticamente ofensiva e moralmente intolerável do corpo humano do jovem guerreiro. A questão ganhou dimensão internacional e, em 1997, o município de Banyoles viu-se forçado a ordenar a retirada do corpo mumificado da exposição que seria de novo enterrado na terra natal (Bagué, 2000: 88).

A narrativa ilustra o sentido evolutivo e disputado da noção de património. $\mathrm{O}$ corpo dissecado foi considerado património enquanto imperou uma noção de civilização e de ciência legitimadas pela prática política e científica do colonialismo. Contudo, num contexto histórico de globalização e de respeito pela diversidade cultural, que é também um contexto de relativismo científico, a exposição pública daquele corpo foi reinterpretada como obscena provocação racista e perdeu a legitimidade enquanto património de que gozara antes.

A conclusão a tirar do episódio é que o património é sempre uma seleção e uma escolha. O seu significado é um valor atribuído em negociação sociocultural. Portanto, resulta de uma ação de reflexividade social que pode ter uma expressão técnica ou mediata. $\mathrm{Na}$ sua expressão técnica, a valorização é fruto do juízo de especialistas e procede dos cânones académicos, técnicos e científicos. $\mathrm{Na}$ expressão mediata da reflexividade, enquanto perdem influência as considerações técnico-científicas, difundem-se os juízos resultantes das visões sociais mais populares e espontâneas, mas nem por isso menos legítimas.

As diversas associações culturais e os movimentos sociais, plataformas e redes sociais surgidas por todo o mundo nos últimos anos, que se dedicam à defesa e proteção do património, são uma clara demonstração da crescente importância desta reflexividade social mediata. Não só exigem tomadas de posição sobre bens culturais que antes eram considerados marginais no seu valor técnico-científico, como se dedicam elas próprias à certificação do valor cultural de tais bens. Tarefa extremamente difícil de resolução para quem possa ter de se confrontar com classificações e narrativas significativas acerca de objetos expostos em museus, especialmente museus etnográficos, com maior ou menor presença de narrativa pós-colonial (Sharp, 2009: 94-97).

Por isso, concluo, numa sociedade plural o que é considerado património depende da presença de sujeitos sociais de origens e orientações políticas e ideológicas diversas e da posição que ocupem na estrutura social. Mas depende 
também da capacidade generalizada e da abertura plural para reconhecimento e valorização dos bens culturais dos outros. Sejam eles os outros grupos ou os outros tempos sociais ou os outros lugares que connosco repartem a sua existência no mundo conturbado da cultura contemporânea.

\section{Referências bibliográficas}

Bagué, Gerard (2000), "El negro de Banyoles ya tiene visado", El País, 1 de julho.

Benjamin, Walter (1992), "A obra de arte na era da sua reprodutibilidade técnica", in Walter Benjamin, Sobre arte, técnica, linguagem e política. Lisboa: Relógio d'Água, 71-113.

Choay, Françoise (2006), A alegoria do património. Lisboa: Edições 70.

Damásio, António (2012), Ao Encontro de Espinosa: As emoções sociais e a neurologia do sentir. Lisboa: Temas e Debates.

Fortuna, Carlos (1997), "Destradicionalição e imagem da cidade", in Carlos Fortuna (org.), Cidade, cultura e globalização. Oeiras: Celta, 231-257.

Fortuna, Carlos (1999), Identidades, percursos e paisagens culturais. Oeiras: Celta.

Fortuna, Carlos (2012), "(Micro)territorialidades: Metáfora dissidente do social”, Terra Plural, 6(1), 199-214.

Fortuna, Carlos; Gomes, Carina; Ferreira, Claudino; Abreu, Paula; Peixoto, Paulo (2012), A cidade e turismo. Dinâmicas e desafios do turismo urbano em Coimbra. Coimbra: Almedina.

Foucault, Michel (1986), "Other Spaces: The Principles of Heterotopia”, Lotus International, 48/49, 9-17.

Freire-Medeiros, Bianca (2010), “'A miséria de uns é a aventura de outros': Pobreza turística e consumo de experiências", in Edson Farias (org.), Práticas culturais nos fluxos e redes da sociedade de consumidores. Brasília: Verbis, 295-316.

Haroche, Claudine (2008), A condição sensivel. Formas e maneiras de sentir no Ocidente. Rio de Janeiro: Contra Capa.

Heinich, Nathalie (2009), La fabrique du patrimoine. De la cathédrale à la petite cuillère. Paris: Éditions de la Maison des Sciences de l'Homme.

Huyssen, Andreas (2003), Present Pasts. Urban Palimpsests and the Politics of Memory. Stanford: Stanford University Press.

Janssen, André; Lagerkvist, Amanda (orgs.) (2009), Strange Spaces: Explorations into Mediated Obscurity. Aldershot: Ashgate.

Jeudy, Henri-Pierre (2008), La machine patrimoniale. Belval: Les éditions Circé.

Le Breton, David (2009), As paixões ordinárias. Antropologia das emoções. Petrópolis: Editora Vozes.

Lowenthal, David (1975), The Past is a Foreign Country. Cambridge: Cambridge University Press. 
Magherini, Graziella (1989), La sindrome di Stendhal. Florença: Ponte Alle Grazie.

Meštrović, Stjepan G. (1993), The Barbarian Temperament. Toward a Postmodern Critical Theory. London/ New York: Routledge.

Nora, Pierre (1986), Les lieux de mémoire. Paris: Gallimard.

Público (2012), "Viagens ao espaço ou ao fundo do mar são agora os limites da aventura", de 15 de abril, por Margarida Santos Lopes.

Riegl, Aloïs (1984), Le culte moderne des monuments: Son essence et sa genèse. Paris: Éditions du Seuil [ed. orig.: 1903].

Rojek, Chris (1993), Ways of Escape. Modern Transformations in Leisure and Travel. Houndmills e London: Macmillan.

Sarmento, João; Brito-Henriques, Eduardo (orgs.) (2013), Tourism in the Global South. Heritages, Identities and Development. Lisboa: Centro de Estudos Geográficos.

Sharp, Joanne P. (2009), Geographies of Postcolonialism. London: Sage.

Silberman, Neil Asher (1996), "Promised Lands and Chosen Peoples. The Politics and Poetics of Archaeological Narrative”, in Philip Kohl e Claire Fawcett (orgs.), Nationalism, Politics and the Practice of Archaeology. Cambridge: Cambridge University Press, 249-261.

Simmel, Georg (1959), "The Ruin”, in Kurt H. Wolff (org.), Essays on Sociology, Philosophy and Aesthetics. New York: Harper \& Row, 259-266 [ed. orig.: 1911].

Sturken, Marita (2007), Tourists of History. Memory, Kitsch, and Consumerism from Oklaboma City to Ground Zero. Durham e London: Duke University Press.

Thai, Wong Chong (1997), "Cacophony. Gratification or Innovation”, in Gülsüm Baydar Nalbantoğlu e Wong Chong Thai (orgs.), Postcolonial Space(s). New York: Princeton Architectural Press, 131-139.

Urry, John (1990), The Tourist Gaze. Leisure and Travel in Contemporary Societies. London: Sage.

Woodward, Christopher (2002), In Ruins. London: Vintage. 
